\title{
An empirical analysis of terrorism and stock market spillovers: the case of Spain.
}

\author{
Ricardo Laborda ${ }^{1}$, Centro Universitario de la Defensa de Zaragoza \\ Jose Olmo, Universidad de Zaragoza and University of Southampton
}

\begin{abstract}
This article assesses spillover effects between terrorist activity and Spanish stock market returns for the period 1993-2017 using the recent methodology proposed by Diebold and Yilmaz (2012). We construct a daily Terror index that reflects terrorist activity of different types of perpetrators: domestic terrorism (ETA) and the international terrorism linked to Islamic extremism. Our static analysis shows that connectedness is important, as it explains about half of the forecast error variance; most of it attributed to shocks from terrorist events on stock market return forecasts. Our dynamic analysis also uncovers an increase in spillover effects between the early period characterized by ETA terrorist attacks to the recent past characterized by Islamic terrorist attacks.
\end{abstract}

Keywords: Terrorism; Type of perpetrator; Spanish stock market returns;

Connectedness; Spillovers; Variance decomposition.

JEL Classification: C22, G1, G41, D74.

\footnotetext{
1 *Corresponding address: Ricardo Laborda. Centro Universitario de la Defensa. Academia General Militar. Ctra. Huesca s/n. 50090. Zaragoza. Phone: +34976739844. Financial support from CUD and CREVALOR is gratefully acknowledged.
} 


\section{Introduction}

The Institute for Economics and Peace defines terrorism as "the threatened or actual use of illegal force and violence to attain a political, economic, religious, or social goal through fear, coercion, or intimidation”. As deployment of effective anti-terror policies requires an understanding of the consequences of terror, recent research has focused on assessing the short- and long-term costs of terrorism for various aspects of the economy and financial markets, and on the utility losses of the people affected.

The main aim of this paper is twofold. First, we investigate the interdependence between the Spanish stock markets and terrorist activity by examining spillover effects between a measure of terrorist activity that we denominate as Terror index and Spanish stock market returns. This relationship has been, to large extent, oversighted in the financial literature. However, it is important for understanding the dynamics of stock markets and, more importantly, for diversification purposes. A high spillover effect from terrorist events to stock market returns can lower the diversification opportunities a portfolio can offer and consequently prompt skilful portfolio managers to generate extra risk-adjusted excess returns or implement an adequate risk management strategy. To proxy the Spanish stock market we consider the IBEX 35. This financial index considers the best thirty-five performing companies in Spain. Given that most of the terrorist activity in Spain took place in the Basque Country we also consider separately the financial returns on the Bilbao stock exchange as another variable proxying the Spanish stock market. In this paper, we attempt to explore and describe the costs and consequences of terrorism on financial markets. We are especially interested in measuring how much of the error variance of short-term forecasts of future stock market returns is due to shocks 
arising from terrorist activity, which is likely to be considered an unforeseen exogenous event.

Second, we analyse the role of the type of perpetrator on the spillovers between terrorist events and stock market returns. Over the period under study, from 1993 to 2017, Spain has been the scene of both domestic terrorist activity by ETA, the main domestic perpetrator of terrorist activity, and terrorist activity by Islamic extremist groups linked to international terrorist organisations. Our Terror index captures terrorist activity by ETA and the various Islamic extremist terrorist attacks occurring not only in Spain but in other parts of Western Europe and the U.S. We classify terrorist activity as being of international origin on the basis of the national identity of the group to which the perpetrator is affiliated (Katos et al., 2011). The terrorism of ETA has been linked to a precise, territorially defined political objective, namely, independence for the Basque Region, whereas Islamic extremists’ terrorist attacks have religious and other political motives. The decision to include terrorist attacks affecting other parts of Western Europe and the U.S. was based on their increasing psychological effect on Spanish investor sentiment, which may strengthen the interdependence between stock markets and terrorism (Drakos, 2010), and the presence of behavioural aspects (Drakos, 2011). Our aim is to study the extent to which the type of perpetrator explains the spillover from terrorism to stock market returns. Could international terrorism have a greater spillover to the stock markets than domestic terrorism? Intuitively, one would expect that international terrorist attacks would have greater effect on Spanish stock market valuations than domestic terrorist attacks, as international terrorism could be considered a global risk factor that can potentially impact the risk premium and expected profitability of Spanish stock markets. The main difficulties in quantifying this type of "catastrophic" risk relate to the challenge of predicting the likelihood and financial consequences of 
terrorist attacks, exposure to terrorism risk and the changing planned terrorist activities (Chesney et al., 2011).

To achieve our objectives we draw on recent literature (Diebold and Yilmaz, 2009, 2012, 2014 and 2015), which provides a measure of interdependence or spillover of asset returns and/or volatilities based on a generalised vector autoregressive framework that is agnostic as to how the interdependence arises. This framework provides several measures of spillover or connectedness that are related to the fraction of the variance in error in hstep-ahead forecasts due to shocks to another variable or variables arising elsewhere. In this paper, we consider the connections between IBEX 35 stock returns, Bilbao stock market returns and a synthetic index that we construct, denominated Terror index. Our measure of connectedness of the Spanish financial markets considers not only stock returns but also one of their possible determinants, namely, terrorist activity.

Our empirical results show that over the period May 1993-December 2017 the spillover effects of terrorism to the Spanish stock market returns were important, with about half of the variance in stock market forecast error coming from connectedness or spillovers with this variable. Unconditionally, shocks arising from the Terror index spill over to the variance of the error of 12-day ahead forecasts of stock returns, but the reverse is not true. As expected, our results reveal that terrorism is an exogenous variable that behaves according to their own motivations unrelated to stock market fundamentals. Furthermore, the temporal dynamics of the connectedness between the Terror index and the Spanish stock market provide insight into how this relationship depends on the terrorist perpetrator. We focus on the dynamics of connectedness that emerge from the analysis of the consequences of ETA and international terrorism-related shocks. We identify two broad periods: one corresponds to the period when the only terrorist attacks were those perpetrated by ETA (from 3th May 1993 to 10th September 2001) and the 
second (from 11th September 2001 terrorist attack onwards) represents the period in which both ETA and Islamic extremists were carrying out terrorist activity. During the latter period, average connectedness and volatility increased. The upsurge in international terrorism has provoked an upward shift in the connectedness between the Terror index and the Spanish stock market that spikes when there are international terrorist attacks. Neither the ceasefires announced by ETA nor the announcement of a permanent cessation of armed activities on 20th October 2011 had a significant immediate impact on total our connectedness measure, which remained almost unchanged. However, ETA's permanent cessation of armed activities has led to a decrease in the total Terror index and the average connectedness with Spanish stock market returns.

The rest of the article is structured as follows. Section 2 provides a brief review of the literature on the financial, economic and psychological consequences of terrorism and the potential links with terrorism and stock market returns spillover effects. Section 3 presents the data and methodological background. Section 4 discusses the empirical application and the connectedness of terrorism and financial markets. Section 5 presents our conclusions.

\section{The economic and psychological consequences of terrorism for financial markets}

Empirical research has focused on the effect of terrorist activity on the stock market, as terrorism can affect expected profits and the risk premium attached to stocks. Abadie and Gardeazabal (2003) confirmed that the ceasefire declared by ETA between 1998 and 1999 had a significant, positive effect on Basque stocks and the stocks of companies with significant business activity in the Basque country, who were therefore more exposed to ETA activity. These stocks outperformed non-Basque stocks once the truce became credible. With respect to the short-term effects of terrorist events, Chesney et al. (2011) 
found that non-parametric techniques were suitable for studying terrorist events and their event-day and post-event window effects. They found that most terrorist attacks had a significant but transitory negative impact on stock markets (see similar results in Barros and Alana, 2009; Arin et al., 2008; Kollias et al., 2011). Terrorist activity had particularly strong, short-term, negative effects on the valuations of airline, travel and insurance companies (Chesney et al., 2011; Kolaric and Schiereck, 2016). Kolaric and Schiereck (2016) found that the airline industry's negative response to terrorist activity depends on specific attributes such as the size and degree of geographical diversification of an airline's activities. On the other hand, terrorist activity can have a positive effect on the stock returns of the Defence industrial sector, as it creates the expectation that there will be a stronger demand for military equipment and defence sector activities are orientated to provide a higher sense of stability and safety (Apergis and Apergis, 2016). As the literature seems to confirm the existence of abnormal returns and higher uncertainty following terrorist incidents, we expect to find shocks to the Terror index spilling over to Spanish stock market returns, producing a short-term increase in connectedness. To the extent that local and international terrorism may be considered as different sources of risk, their impact on stock market return spillovers may also differ. More specifically, international terrorism is a global risk factor with greater potential to increase the connectedness between terrorism and financial markets.

In this paper, we also consider Islamic extremist terrorist attacks affecting Spain, the rest of Western Europe and the United States, as we consider these different events to be related in various ways that, we conjecture, increase spillovers from terrorism to stock market returns. First, these attacks have a great psychological effect on Spanish investor sentiment. These terrorist attacks have received more detailed coverage in Spanish media than international terrorist attacks occurring in other parts of the world, reflecting their 
higher social impact (Rodriguez et al., 2009). Related to this, Jetter (2017) provides evidence showing that media coverage of terrorism positively relates to subsequent terrorist attacks, which allows terrorist groups to cause larger fear and promotion of their agenda. Following this evidence, we hypothesise that there are correlations between the probabilities of Islamic extremist terrorist attacks in Western Europe and the U.S., because such attacks attract wide media coverage in these countries and are driven by similar religious and political motives. From the 11th September 2001 terrorist attack onwards, Islamic extremism terrorists have attacked several Western European countries, showing that 11/9 terrorist attack was not a one-off event. This has had consequences for perceptions of insecurity and has prompted individuals to re-evaluate the likelihood of being affected by terrorist attacks. Finally, international terrorist attacks can affect Spanish stock market valuations because international terrorism can be considered a global risk factor that can potentially impact risk premiums and the expected profitability of Spanish stock markets.

Second, the influence of terrorism shocks on financial markets also depends on behavioural factors. Drakos (2011) shows that behavioural factors explain why abnormal returns following a terrorist attack in one place affect markets in other countries. On the one hand, a more severe history of terrorism, as in Spain, increases the likelihood and magnitude of a negative stock market reaction to terrorist attacks, in accordance with the concept of memory-based utility and the availability heuristic ${ }^{2}$. On the other hand, the observed spillover from terrorist shocks to other countries is also due to the phenomenon known as social amplification of risk (Slovic, 1987) which takes place at an international

\footnotetext{
${ }^{2}$ Drakos (2011) explained that reactions to a stimulus are affected by memory-based utility, which treats the subject's retrospective evaluation of past episodes and situations as valid data. The availability heuristic is a term used to describe how individuals judge the probability of an event: according to the ease with which one can imagine similar events or by the number of such instances are readily retrieved from memory.
} 
level as terrorist attacks are highly feared, and considered an unknown source of risk. The existence of a psychological impact of terrorism on investor sentiment should have a positive spillover effect from terrorism to stock market returns. Studies measuring the economic consequences of terrorism have shown that death, injury and capital destruction are the most direct and visible effects of a terrorist attack and the most easily measured, but terrorism also has long-lasting, indirect economic effects. Terrorism has a negative effect on political stability, adversely affecting both an economy's gross domestic product (GDP) per capita growth and its long-term potential for growth (Abadie and Gardeazabal, 2003; Eckstein and Tsiddon, 2004; Mehmood, 2014). A more subtle effect of terrorism is that it can also affect the preferences of economic agents and hence their economic decisions; because terror endangers life it diminishes the value of the future relative to the present (Eckstein and Tsiddon, 2004). After an upsurge in terrorist activity economic activity is redirected from investment spending towards government spending (Bloomberg et al., 2004), usually orientated to an increase safety measures, which is a key driver of the individual consumption and investment decision making process (Eckstein and Tsiddon, 2004). Terrorism can also lead to changes in investment levels and its composition, reducing investment in non-traded capital goods and non-residential construction, which are considered particularly risky in a politically unstable environment (Fielding, 2003).

Consequently, terrorist activity has a psychosocial effect that exerts a negative influence on consumer confidence. Drakos and Kallandranis (2015) showed that unforeseen terrorist attacks have a negative impact on economic sentiment, in particular on consumer confidence, after controlling for economic drivers of sentiment in the post9/11 period. These authors showed that as economic sentiment can predict macroeconomic variables, and is affected by terrorism, there is a negative association 
between terrorism and the performance of the economy. Another clear example is the negative relationship between terrorist activity and international or national tourism, because tourists are less likely to choose a destination where the perceived threat of terrorist attacks is high (Enders and Sandler, 1991; Drakos and Kutan, 2003; Dorta et al., 2016). Assuming that terrorism has a negative effect on the economy, we would expect shocks to the Terror index would spill over to various macroeconomic variables but this interesting possibility is outside the scope of this paper.

\section{Data and Methodology}

This section describes the data used in our empirical analysis and explains the procedure used to construct the Terror index. We also provide a summary of the Diebold and Yilmaz (2012) connectedness index methodology.

\subsection{Data}

We use two data sets. The first set comprises daily closing prices of the IBEX 35 financial index and the Bilbao stock exchange as reported by Bloomberg. The IBEX 35 is the usual benchmark for the Spanish stock market and is a value-weighted index consisting of the 35 stocks with the largest market values. The Bilbao stock exchange is a minor exchange that, nevertheless, reflects very closely the development of the financial, industrial and economic activity of the Basque Country, acting as the channel through which companies in the region obtain funds for large investment projects. Barros and Alana (2009) used data on the Bilbao stock exchange to analyse the negative effects of violence in the Basque Country - linked to ETA activity - on the financial activity of the region, showing that violence reduces stock market returns. Our data set covers the period May 1993-December 2017. We computed logarithmic daily percentage index returns. Table 1

reports the main summary statistics and unit root tests that reject the null hypothesis of non-stationarity. 
The second data set comprises information on daily terrorist events. We construct a database of terrorist events from the Global Terrorism Database (GTD hereafter) ${ }^{3}$. The GTD includes all terrorist attacks, defining a terrorist attack as an intentional incident, entailing some level of violence or immediate threat of violence and perpetrated by subnational actors. Incidents must also meet at least two of the following three criteria: 1) aimed at attaining a political, economic, religious or social goal, 2) evidence of intent to intimidate a larger audience than the immediate victims and 3) outside the context of legitimate warfare activities. We consider terrorist attacks by two types of perpetrator: ETA and Islamic extremist. The database includes terrorist attacks by ETA that resulted in deaths ${ }^{4}$ that the GTD attributes to 'Basque Fatherland and Freedom'. It also includes Islamic extremist attacks that have caused deaths in Spain, the rest of Western Europe and the U.S. in the same period.

\section{[Insert table 1 about here]}

ETA is a nationalist and separatist terrorist group that emerged in the 1960s to resist Franco's dictatorship and its main political objective was to promote the establishment of an independent Basque state. ETA killed 829 people between 1968 and 2010 and announced a permanent cessation of armed activities on 20th October 2011. Tables 2 and 3 report deaths caused by ETA and Islamic extremist groups in the period May 1993-December 2017. Over this period, Islamic terrorist attacks claimed a larger amount of victims than ETA. The decrease in ETA victims during our observation period is due to two factors: the ETA strategy that put the emphasis on state representatives as targets to exert a greater impact on public opinion and increased effectiveness of the Spanish counter-terrorist effort. The immediate objective of Islamic extremist attacks

\footnotetext{
${ }^{3}$ Global terrorism Database [Data file]. Retrieved from http://www.start.umd.edu/gtd.

${ }^{4}$ Leoniso et al. (2017) provide a summary of the Basque conflict and overview of ETA's campaign of political violence, extortion and threats.
} 
seems to be to kill and injure as many people as possible, regardless of the type of target, in order to try to disrupt and destroy the daily economic and social routine of targeted metropolitan centres. Spain was directly affected by Islamic extremist attacks during our observation period. The $11^{\text {th }}$ March 2004 train bombings, which caused 193 deaths, were carried out by Islamic extremists, although ETA was initially held responsible. The terrorist attacks in Barcelona and Cambrills on the 17th and 18th August 2017 claimed 16 lives.

\section{[Insert Tables 2 and 3 about here]}

The Terror index is computed as follows. For each day t, we compute a terror score based on the weighted sum of number of deaths over the prior five years, progressively down-weighting past deaths on an annual basis. The definition of terrorism as "the threatened or actual use of illegal force and violence to attain a political, economic, religious, or social goal through fear, coercion, or intimidation” suggests that terrorism is not only the physical act of an attack but also the psychological impact it has on a society for many years after (Global Terrorism Index 2017). We use the method recommended by the Institute for Economics and Peace to estimate the psychological impact of terrorist attacks and included this in the index score. We assigned a weight of $52 \%$ to the total number of deaths in the index year (year $t$ ), $36 \%$ to the number of deaths in $t-1,13 \%$ to the number of deaths in $t-2,6 \%$ to the number of deaths in $t-3$ and $3 \%$ to the number of deaths in $t-4$. The Terror index is the natural log of the current terror score. Thus, we try to capture not just the direct impact of terrorist attacks but the longer term psychological effects that terrorist attacks have on society (Global Terrorism Index, 2017). Figure 1 plots the Terror index.

[Insert Figure 1 about here] 


\subsection{Measure of spillover effects}

Our interest is mainly on measuring the spillover from shocks to the Terror index to Spanish stock market returns (and vice versa). Diebold and Yilmaz (2009) introduced a spillover index based on a forecast variance decomposition of vector autoregressive processes (VARs) that relies on a Cholesky factor identification. Diebold and Yilmaz (2012) build on their previous contribution and develop an improved spillover index. This index is based on a decomposition of the forecast error variance from a VAR model that is insensitive to variable ordering and takes into account not just total spillover effects but also the direction of the spillovers. Given the set of variables, $Y_{t}=\left[R_{I B E X} 35, R_{\text {Bilbao, }}\right.$ Terror Index $]$, where $R_{I B E X} 35$ is the daily return on the IBEX 35, $R_{\text {Bilbao }}$ is the daily return on the Bilbao Stock market exchange and Terror index is our measure of terrorist activity constructed as detailed above, we fit a standard vector autoregressive VAR model to the series. Using series data up to and including time $t$. We then establish an $h$-period-ahead forecast and decompose the error variance of the forecast for each component, with respect to shocks from the same or other components at time $t$. We calculated the Diebold and Yilmaz (2012) connectedness measure, based on assessment of the percentage variance in forecast errors in various locations that can be attributed to shocks arising elsewhere.

The approach involves assessing the percentage of variance in forecast error due to shocks arising elsewhere. Let $Y_{t}=\left[R_{I B E X} 35, t, R_{\text {Bilbao, } t}\right.$, Terror Index $\left.t\right]$ denote a time-series vector of dimension $N=3$, following a $\operatorname{VAR}(p)$ model as

$$
Y_{t}=\sum_{i=1}^{p} \phi_{i} Y_{t-i}+\varepsilon_{t,} \quad t=1,2, \ldots . T
$$


where $\varepsilon_{t} \sim N(0, \Sigma)$ is a vector of independently and identically distributed disturbances. Assuming that the VAR process is covariance stationary, the moving-average representation exists and is

$$
Y_{t}=\sum_{i=0}^{\infty} A_{i} \varepsilon_{t-i}
$$

where the $\mathrm{N} \times N$ coefficient matrices obey the following recursive relationship:

$$
A_{i}=\phi_{1} A_{i-1}+\phi_{2} A_{i-2}+\ldots .+\phi_{p} A_{i-p}
$$

where $A_{0}=I_{N}$ and $A_{i}=0$ for $i<0$.

Diebold and Yilmaz (2012) identified financial and macroeconomic connectedness based on the $h$-step ahead forecast error variance decomposition. These authors define own variance shares as $d_{i i}$, the $h$-step forecast error variance decomposition in forecasting $Y_{i}$ due to shocks to $Y_{i}$, for $i=1,2, \ldots . N$. Similarly, cross-variance shares measure the spillover effects and are formally defined as the variance in the $h$-step ahead forecast error of forecasting $Y_{i}$ due to shocks to $Y_{j}$, for $i, j=1,2, \ldots . N$, such that $i \neq j$. Diebold and Yilmaz (2012) used the generalised variance decomposition framework of Koop et al. (1996) and Pesaran and Shin (1998), which enables the computation of orderinvariant variance decompositions. Therefore, the generalised variance decomposition does not require orthogonalised shocks by assuming simultaneous correlated shocks using the historically observed distribution under a normality assumption.

We are interested in applying this methodology for measuring Spanish stock market returns and Terror index spillover effects, in particular, the spillover from shocks to the Terrorism index to Spanish stock market returns. Our research questions are the following: What fraction of the forecast error variance of future stock market returns is 
due to the shocks affecting the Terror index? Interestingly, the methodology proposed in Diebold and Yilmaz (2012) also allows us to measure spillovers from shocks to the Spanish stock market returns to the Terror index.

The $h$-step ahead error variance decomposition, $\theta_{i, j}^{g}(H)$, of the generalised VAR framework can be calculated as follows (Diebold and Yilmaz, 2012):

$$
\theta_{i, j}^{g}(H)=\frac{\sigma_{j j} \sum_{h=0}^{H-1}\left(e_{i}^{\prime} A_{h} \Sigma e_{j}\right)^{2}}{\sum_{h=0}^{H-1}\left(e_{i}^{\prime} A_{h} \Sigma A_{h}^{\prime} e_{i}\right)^{2}}
$$

where $\Sigma$ is the variance matrix for the error term vector $\varepsilon$ in the non-orthogonalised VAR, $\sigma_{j j}$ is the $j^{\text {th }}$ diagonal element of $\Sigma$, and $e_{i}$ is the selection vector with unity at its ith element and zero elsewhere. As the shocks are not necessarily orthogonal in the generalised variance decomposition, sums of the forecast error variance contributions are not necessarily unity, $\left(\sum_{j=1}^{N} \theta_{i, j}^{g}(H) \neq 1\right)$. Diebold and Yilmaz (2012) normalised each entry in the variance decomposition matrix by the row sum:

$$
\tilde{\tilde{\theta}}_{i, j}^{g}(H)=\frac{\theta_{i, j}^{g}(H)}{\sum_{j=1}^{N} \theta_{i, j}^{g}(H)}
$$

and, consequently $\sum_{j=1}^{N} \tilde{\tilde{\theta}}_{i, j}^{g}(H)=1$ and $\sum_{i, j=1}^{N} \tilde{\tilde{\theta}}_{i, j}^{g}(H)=N$.

The full set of variance decompositions produces the connectedness table (see Table 4), $D=\left[d_{i j}=\tilde{\theta_{i, j}^{g}}(H)\right]$, which allows us to compute the main measures of connectedness between the Terror index and Spanish stock market returns.

[Insert Table 4 about here] 
There are $N^{2}-N$ pairwise directional connectedness from $j$ to $i$ defined as

$$
C_{i \longleftarrow j}=d_{i j}=\tilde{\theta_{i, j}^{g}}(H)
$$

$C_{i \longleftarrow j}$ represents the fraction of the $H$-step-ahead error variance in variable $i$ due to shocks arising from variable $j$. In general $C_{i \longleftarrow j} \neq C_{j \longleftarrow i}$, so it is interesting to define the $\frac{N^{2}-N}{2}$ net pairwise directional connectedness as

$$
C_{i j}=C_{j \longleftarrow i}-C_{i \longleftarrow j}=d_{j i}-d_{i j}=\tilde{\theta_{j i}^{g}}(H)-\tilde{\theta_{i, j}^{g}}(H)
$$

The off-diagonal row and column sums, labelled "from" and "to" are the $2 N$ total directional connectedness measures. The total directional connectedness from others to $i$ is

$$
C_{i \longleftarrow}=\sum_{\substack{j=1 \\ i \neq j}}^{N} d_{i j}=\sum_{\substack{j=1 \\ i \neq j}}^{N} \underset{\tilde{\theta_{i, j}^{g}}}{\tilde{g}}(H)
$$

The total directional connectedness from $j$ to others is

$$
C_{\bullet \longleftarrow j}=\sum_{\substack{i=1 \\ i \neq j}}^{N} d_{i j}=\sum_{\substack{i=1 \\ i \neq j}}^{N} \underset{\theta_{i, j}^{g}}{\approx}(H)
$$

Hence, there are $N$ total directional measures, $N$ “to others" and $N$ “from others".

The net total directional connectedness is defined as

$$
C_{i}=C_{\bullet \longleftarrow i}-C_{i \longleftarrow} .
$$

such that there are $N$ net total directional connectedness measures. 
The grand total of the off-diagonal entries in $D$, which sums the "from" column and the "to" row, provides a measure of total connectedness that corresponds to the lower right cell of the connectedness table, as a percent of total variation

$$
C=\frac{\sum_{\substack{i, j=1 \\ i \neq j}}^{N} \tilde{\tilde{\theta}}_{i, j}^{g}(H)}{N}
$$

In our empirical application $N=3, H=12$ and $p=3$.

\section{Empirical results}

In this section, we report the empirical results of our analysis of connectedness between the Terror index and the Spanish stock market. First, we present the static or unconditional connectedness using the generalised variance decomposition. Second, we analyse the dynamics of the Terror/Spanish stock market connectedness via rolling window estimation.

\subsection{Unconditional patterns: the full-sample Terror/Spanish stock market connectedness table}

In this section we report the full-sample analysis of Terror/Spanish stock market connectedness for the observation period (May 1993-December 2017). Table 5 reports estimates of Terror/Spanish stock market connectedness obtained through the generalised variance decomposition. We decompose the total Terror/Spanish stock market connectedness into all the forecast error variance components for variable $i$ coming from shocks to variable $j$, for all $i$ and $j$. The $i j$ entry of Table 4 is the estimated contribution to the forecast error variance of variable $i$ coming from innovations to variable $j$. The estimate of Terror/Spanish stock market connectedness is based on a vector 
autoregressive process of order 3 and generalised variance decompositions of 12-day ahead forecast errors (Diebold and Yilmaz, 2015).

[Insert Table 5 about here]

An important result that emerges from Table 4 is that about half of the forecast error variance comes from connectedness or spillovers $(C=51.6 \%)$. Hence, connectedness or spillovers are important, on average, or unconditionally in our sample, especially for Spanish stock market returns. To confirm this point, Table 4 shows in the “connectedness to others” row that the IBEX 35 and the Bilbao stock market have very similar "to" connectedness, about 20\%. The Terror index shows the highest "to" connectedness, reaching a value of $C \longleftarrow_{\text {Terror Index }}=115 \%$. Shocks arising from the Terror index have a clear spillover to errors in the 12-day ahead forecast of Spanish stock market returns, but the reverse is not true. Interestingly, Table 2 reports that Spanish stock market returns have a "from" connectedness of about 75\%, mainly due to the impact of shocks to the Terror index. However, the Terror index has almost $0 \%$ "from" connectedness, implying that shocks to Spanish stock market returns have negligible unconditional impact on the Terror index. This result is plausible, as one would expect the behaviour of terrorist groups to be driven by motivations unrelated to stock market fundamentals. Thus Spanish stock market returns show negative net directional connectedness; in other words, they are net recipients of shocks from the Terror index, which has a very high net connectedness $\left(C_{\text {Terror Index }}=115.1 \%\right)$ and is a net transmitter of shocks. There is clear spillover effects from terrorist activity to the Spanish stock market returns but not vice versa.

\subsection{Conditional patterns: Terror/Spanish stock market connectedness dynamics}


The previous section provides important information about aspects of the Terror/Spanish stock "average" market connectedness in our data set. However, the fixed-parameter model represented in Table 4 is unlikely to apply over the entire observation period, as the stock market goes through cycles and the intensity of terrorist activity also varied over the period.

In this section, we focus on the temporal dynamics of the Terror/Spanish stock market connectedness as the full-sample unconditional analysis may overlook important interactions (Diebold and Yilmaz, 2015). To do this, we follow Diebold and Yilmaz (2009, 2012, 2014 and 2015) and carry out a dynamic analysis using 200-day rollingsample windows. This analysis allows us to examine the extent and nature of temporal variation in spillovers as described by the corresponding time series of Spillover indices, represented graphically in Spillover plots (Diebold and Yilmaz, 2009). This approach allows us to analyse the dynamics of connectedness that emerges as a consequence of shocks to the Terror index, which are related to domestic (ETA) and international (Islamic extremist) terrorist activity. We analyse the total connectedness between the Terror index and Spanish stock market returns in three periods: 1) the domestic terror-only period spanning from 31th January 1994 to 10th September 2001, 2) the domestic plus international terror period, from 11th September to 5th September 2010 and 3) the international terror-only period spanning from 6th September 2010 onwards.

In Figure 2, we plot the total Terror/Spanish stock market connectedness using 200-day rolling-sample windows. Visual inspection of the total connectedness plot reveals interesting patterns. We can identify two main periods: one corresponds to the domestic terror-only period, from 31th January 1994 to 10th September 2001, and the second starts with the 11th September 2001 terrorist attack and includes domestic and international terrorist activity. The most remarkable finding that emerges from Figure 2 
is that during the latter period average connectedness and volatility increased. The spillover between Spanish stock market returns and the Terror index was higher than in the domestic terror period; in other words, the interdependence between the Terror index and the Spanish stock market increased once Islamic extremist terrorism emerged.

\section{[Insert Figure 2 about here]}

During most of the domestic terror-only period, 31th January 1994 to 10th September 2001, total Terror/Spanish stock market connectedness fluctuated between 17\% and 41\%. Between 11th September 2001 and 5th September 2010 (when the last ETA victim was killed), the period of domestic plus international terror, the total Terror/Spanish stock market connectedness fluctuated between $31 \%$ and $67 \%$ and the total average connectedness jumped from 35\% to 52\%. The upsurge in international terrorism appears to have provoked an upward shift in total Terror/Spanish stock market connectedness. From 6th September 2010 onwards, the international terror period, the total Terror index and Spanish stock market returns connectedness fluctuated between $32 \%$ and $64 \%$ and the average total connectedness dropped to $44 \%$. Our estimation shows that the total Terror/Spanish stock market connectedness was higher in the period of international terror than in the domestic terror period. Although the average total connectedness was higher than the value reached during the domestic terror period, the permanent cessation of ETA's armed activities has led to a decrease in the average of the total Terror index and Spanish stock market returns connectedness.

It is notable that total Terror/Spanish stock market connectedness jumps when there are international terrorist attacks ${ }^{5}$. The total connectedness increased from $41 \%$ to

\footnotetext{
${ }^{5}$ Other events that have had a significant impact on total Terror index and Spanish stock market returns connectedness are related to the tech bubble in 2000, the FED tightening process during 2006, the subprime crisis and the Eurozone debt crisis of 2010 and 2011.
} 
$67 \%$ in the New York terrorist attack of 11th September 2001; from 38.90\% to 59.75\% in the Paris terrorist attacks of November 2015; from $45.58 \%$ to $61.76 \%$ in the Paris terrorist attacks of January 2015 and from 35.65\% to $47.05 \%$ in the Barcelona and Cambrills terrorist attacks of August 2017. Interestingly, the bombings on 11th March 2004 in Madrid and 7th July 2005 in London led to a decrease in total Terror/Spanish stock market connectedness. Total connectedness decreased from $63.17 \%$ to $57.19 \%$ during the 11th March 2004 Madrid bomb attack and from 56.09\% to 45.82\% in the London terrorist attack. In both cases total connectedness reached remarkable values - over $50 \%$ - during the days preceding the attacks.

Only one ETA terrorist attack produced a significant increase (35\%) in total Terror/Spanish stock market connectedness from a low $17.54 \%$ to $23 \%$ : on the 21th January 2000 an ETA attack killed one person, the first to die since ETA had declared the end of its ceasefire in November 1999 (the ceasefire had started in September 1998). This terrorist attack therefore had a special effect on Spanish stock market sentiment. Interestingly, neither the ceasefires (and corresponding truce periods) announced by ETA on September 16 1998, or March 22 2003, nor the announcement of a permanent cessation of armed activities on 20 October 2011 had a significant instantaneous impact on the total Terror index and Spanish stock market returns connectedness, which remained almost unchanged.

We analysed directional connectedness plots (see Figures 3-5) to gain insight into total Terror/Spanish stock market connectedness. These plots show that the net connectedness of the Terror index, the IBEX 35 and the Bilbao Stock Exchange increased substantially from the 11th September 2001 terrorist attack onwards. Over this period the "from" connectedness of the IBEX 35 and the Bilbao Stock Exchange and the "to" connectedness of the Terror index jumped significantly. Their net connectedness also 
moved in opposite direction from very negative "net” connectedness of the IBEX 35 and the Bilbao Stock Exchange to very positive "net” connectedness of the Terror index. In other words, in this period shocks to the Terror index showed greater spillover effects to Spanish stock market returns, whose forecast error variance can mostly be attributed to Terror index shocks. The increase in shocks to the Terror index and the higher interdependence with the stock markets could explain the changes observed in the dynamics of the connectedness measures.

During the domestic terror period the valences of the net connectedness of the Terror index, the IBEX 35 and the Bilbao Stock Exchange are the same as in the period from 11th September 2001 onwards, but lower in magnitude. We can infer from this that connectedness is affected by the eruption of international terrorist attacks in Occidental countries. Hence, the higher spillover from international terrorist activity to Spanish stock market returns relative to the spillover effects from ETA activity could be attributed to the capacity of the former to affect all international stock market valuations, thereby reducing diversification opportunities, which contrasts with the effects of ETA's domestic terrorism, which are confined to Spanish stock market returns. The difference can be also attributed to amplification of the psychological effect of the international terrorist attacks on investor mood because they are perceived as a new type of terrorist threat.

\section{[Insert Figures 3-5 about here]}

It is also notable that throughout the observation period the Terror index is almost unaffected by shocks arising in the stock markets. This suggests that terrorist activity is unrelated to stock market fundamentals because the perpetrators are pursuing their own goals. 
Finally, we carry out a sensitivity analysis of the total connectedness index with respect to the choice of VAR model $(L=1,3,6)$ and forecast horizon $(h=6,12,18)$ for calculation of the variance decompositions of the estimated VAR. For each forecast horizon considered, we plotted the total index using $L=1$, 3, 6. Figure 6 clearly shows that the total Terror index and Spanish stock market returns connectedness is robust to the choice of forecast horizon and the order of the VAR model, as all the plots show the same pattern of changes in total connectedness.

[Insert Figure 6 about here]

\section{Conclusion}

This paper examines the connection between terrorist activity and Spanish stock market returns, drawing on recent research on measures of connectedness and spillover effects (Diebold and Yilmaz, 2009, 2012, 2014 and 2015). We constructed a Terror index that captures the activities of two different types of perpetrator: domestic terrorists (ETA) and international terrorist groups (Islamic extremists) that have targeted Spain, the rest of Western Europe and the U.S. in recent periods. In doing so, we try to capture the psychological effect of the various acts of Islamic extremist terrorism, which are based on shared religious and political motives, on the daily activity of Occidental countries. Our results confirm that shocks arising from the Terror index have a clear spillover to errors in 12-day ahead Spanish stock market return forecasts, but the reverse is not true. Our dynamic analysis shows that the sudden upsurge in Islamic extremist terrorism has provoked a corresponding upsurge in the connectedness of terrorist activity and Spanish stock market returns, thus emphasising the significance of international terrorism as a potential global risk factor for stock markets. The spillover effects of terrorist attacks 
should be taken into account by portfolio managers as they can negatively affect portfolio diversification opportunities and managers' ability to hedge against risks to their portfolios.

The agenda for future research should include investigation of the direct and indirect effects of terrorism, more broadly construed, on Terror/Spanish stock market connectedness. In this paper, we have only considered terrorist incidents in which there were fatalities, but the analysis could be extended to examine the effects of non-fatal incidents. We will also study the asset allocation implications of total Terror/Spanish stock market connectedness. It would be also worth investigating the relationship between future economic activity and the spillover from terrorism to stock market returns. 
Table 1. Summary statistics and unit roots. Daily Spanish stock market returns.

Panel A. Summary statistics.

IBEX 35

Bilbao Stock exchange

market

\begin{tabular}{lcc}
\hline Mean & $0.020 \%$ & $0.023 \%$ \\
Median & $0.039 \%$ & $0.02 \%$ \\
Maximum & $13.48 \%$ & $20.29 \%$ \\
Minimum & $-13.18 \%$ & $-12.31 \%$ \\
Std. deviation & $1.415 \%$ & $1.371 \%$ \\
Skewness & -0.15 & 0.33 \\
Kurtosis & 5.94 & 12.69
\end{tabular}

The table reports the main statistics for the daily IBEX 35 and Bilbao stock exchange market returns over the May 1993-December 2017 observation period. We computed logarithmic daily percentage index returns using daily closing prices of the IBEX 35 financial index and the Bilbao stock exchange as reported by Bloomberg. The IBEX 35 is the usual benchmark for the Spanish stock market and is a value-weighted index consisting of the 35 stocks with the largest market values. The Bilbao stock exchange is a minor exchange that, nevertheless, reflects very closely the development of the financial, industrial and economic activity of the Basque Country, acting as the channel through which companies in the region obtain funds for large investment projects.

Panel B. Unit root tests.

\begin{tabular}{lcc} 
& (rho-1) & Critical value \\
\hline IBEX 35 & -22.45 & -5.490 \\
$\begin{array}{l}\text { Bilbao Stock exchange } \\
\text { market }\end{array}$ & -39.76 & -5.490 \\
Index Terror & -6.059 & -5.490
\end{tabular}

The table reports the Clemente et al. (1998) test for a unit root with a double change in mean using an innovative outlier. 
Table 2. The table reports deaths caused by ETA in the period May 1993-December 2017. We construct a database of terrorist events from the Global Terrorism Database (GTD). The GTD includes all terrorist attacks, defining a terrorist attack as an intentional incident, entailing some level of violence or immediate threat of violence and perpetrated by sub-national actors. Incidents must also meet at least two of the following three criteria: 1) aimed at attaining a political, economic, religious or social goal, 2) evidence of intent to intimidate a larger audience than the immediate victims and 3) outside the context of legitimate warfare activities. The database includes terrorist attacks by ETA that resulted in deaths that the GTD attributes to 'Basque Fatherland and Freedom'.

Source: GTD

Year

1993

1994

1995

1996

1997

1998

1999

2000

2001

2002

2003

2004

2005

2006

2007

2008

2009

2010

2011

\section{Number of deaths}

14

12

15

5

13

6

0

23

15

5

3

0

0

2

2

4

3

1

0 
2012

0

2013

0

2014

0

2015

0

2016

0

2017

0 
Table 3. The table reports deaths caused by Islamic extremist groups in the period May 1993-December 2017. We construct a database of terrorist events from the Global Terrorism Database (GTD). The GTD includes all terrorist attacks, defining a terrorist attack as an intentional incident, entailing some level of violence or immediate threat of violence and perpetrated by sub-national actors. Incidents must also meet at least two of the following three criteria: 1) aimed at attaining a political, economic, religious or social goal, 2) evidence of intent to intimidate a larger audience than the immediate victims and 3) outside the context of legitimate warfare activities. We consider Islamic extremist attacks that have caused deaths in Spain, the rest of Western Europe and the U.S. in the same period.

Source: GTD

Year

2001

2002

2003

2004

2005

2006

2007

2008

2009

2010

2011

2012

2013

2014

2015

2016

2017

\section{Number of deaths}

2979

1

0

193

56

0

2

0

14

1

2

6

8

7

181

175

38 
Table 4. The table reports the schematic connectedness table that proves central for understanding the various connectedness measures and their relationships. Its main upper-left block matrix of dimension $\mathrm{YxN}$ contains the variance decompositions, called the "variance decomposition matrix", $D=\left[d_{i j}=\tilde{\theta_{i, j}^{g}}(H)\right]$, The connectedness table augments $\mathrm{D}$ with a rightmost column containing row sums, a bottom row containing column sums, and a bottom-right element containing the grand average, in all cases for $i$ different from $j$.

\begin{tabular}{|c|c|c|c|c|c|}
\hline & $Y_{1}$ & $Y_{2}$ & $\bullet$ & $Y_{N}$ & From Others \\
\hline$Y_{1}$ & $d_{11}={\tilde{\theta_{1,1}}}^{g}(H)$ & & . & $d_{1 N}=\tilde{\tilde{\theta}}_{1, N}^{g}(H)$ & $\sum_{\substack{j=1 \\
j \neq 1}}^{N} \widetilde{\theta_{1, j}^{g}}(H)$ \\
\hline$Y_{2}$ & $d_{21}=\tilde{\theta}_{2,1}^{g}(H)$ & $d_{22}=\tilde{\tilde{\theta}}_{2,2}^{g}(H)$ & 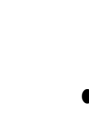 & $d_{2 N}=\tilde{\tilde{\theta}}_{2, N}^{g}(H)$ & $\sum_{\substack{j=1 \\
j \neq 2}}^{N} \tilde{\tilde{\theta_{2, j}}}(H)$ \\
\hline$\bullet$ & $\bullet$ & $\bullet$ & $\bullet$ & $\bullet$ & $\bullet$ \\
\hline$\bullet$ & • & $\bullet$ & - & - & $\bullet$ \\
\hline$Y_{N}$ & $d_{N 1}=\tilde{\tilde{\theta}}_{N, 1}^{g}(H)$ & $d_{N 2}=\tilde{\theta}_{N, 2}^{g}(H)$ & - & $d_{N N}=\tilde{\tilde{\theta}}_{N, N}^{g}(H)$ & $\sum_{\substack{j=1 \\
j \neq N}}^{N} \theta_{N, j}^{\tilde{g}}(H)$ \\
\hline $\begin{array}{c}\text { To } \\
\text { Others }\end{array}$ & $\sum_{i=1}^{N} \underset{i=1}{\tilde{\theta_{i, 1}^{g}}}(H)$ & $\sum_{i=2}^{N} \underset{i=1}{\tilde{\theta_{i, 2}^{g}}}(H)$ & & $\sum_{i \neq N}^{N} \underset{i=1}{\tilde{\theta}} \theta_{i, N}^{g}(H)$ & $1 / N \sum_{i, j=1}^{N} \tilde{\tilde{\theta}}_{i, j}^{g}(H)$ \\
\hline
\end{tabular}


Table 5. The table reports the connectedness table of the Terror index and Spanish stock market returns.

\begin{tabular}{ccccc} 
& IBEX 35 & $\begin{array}{c}\text { Bilbao Stock } \\
\text { market }\end{array}$ & Terror index & From Others \\
& & & & \\
\hline IBEX 35 & 23.9 & 19.5 & 56.6 & 76.1 \\
Bilbao Stock & 20.1 & 21.2 & 58.7 & 78.8 \\
market & 0.01 & 0.01 & 98.8 & 0.02 \\
Terror index & & & & \\
\hline To Others & 20.1 & 19.5 & 115.3 & \\
& & & & \\
Net & -56 & -59.3 & 115.1 & 51.6
\end{tabular}

Table 5 reports a measure of the connectedness of the Terror index and Spanish stock market returns obtained through a generalised variance decomposition. This measure of the connectedness of the Terror index and Spanish stock market returns is based on a vector autoregression of order 3 and generalised variance decompositions of 12-day ahead forecast errors. Each cell in the 3x3 matrix section of the table reports the relative (in percentage terms) contribution of the column variable shocks to variance in the forecast error for the row variable. Each cell in the "from Others" column reports the total variance in forecast error that is attributable to other variables. Each cell in the "To Others" row reports the sum of the contributions of each variable to variance in the forecast errors for all other variables. The net connectedness row reports the difference between the relevant "To Others" and "From Others" cells. The total connectedness index is the number in the lower right corner and is equal to the average of the elements of the "From Others" column and the "To Others" row. 


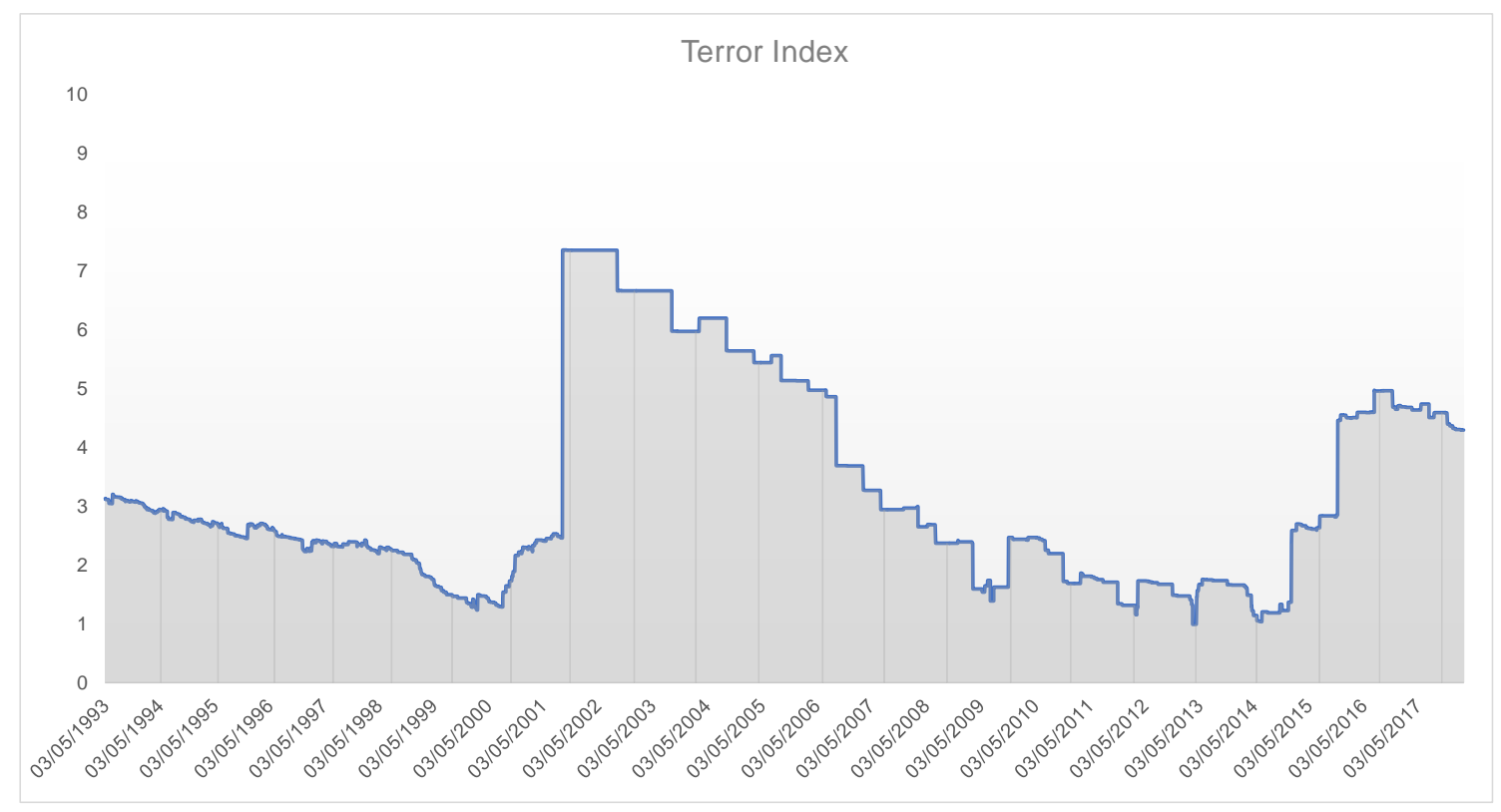

Figure 1. The Terror index is constructed as follows. For each day $t$, we calculate a current terror score based on the sum of the number of killed people over the prior five years, progressively down-weighting previous years. Following the Global Terrorism Index 2017 methodology developed by the Institute for Economics \& Peace we assign a weight of $52 \%$ to deaths in the current year $(i), 36 \%$ to deaths in year $i-1$, $13 \%$ to deaths in year $i-1,6 \%$ to deaths in year $i-2$ and $3 \%$ to deaths in year $i-4$. The Terror index is the natural log of the current terror score. In using this method we were attempting to take into account not only the immediate effects of an attack but also the longer term psychological impact that terrorist attacks have on a society. 


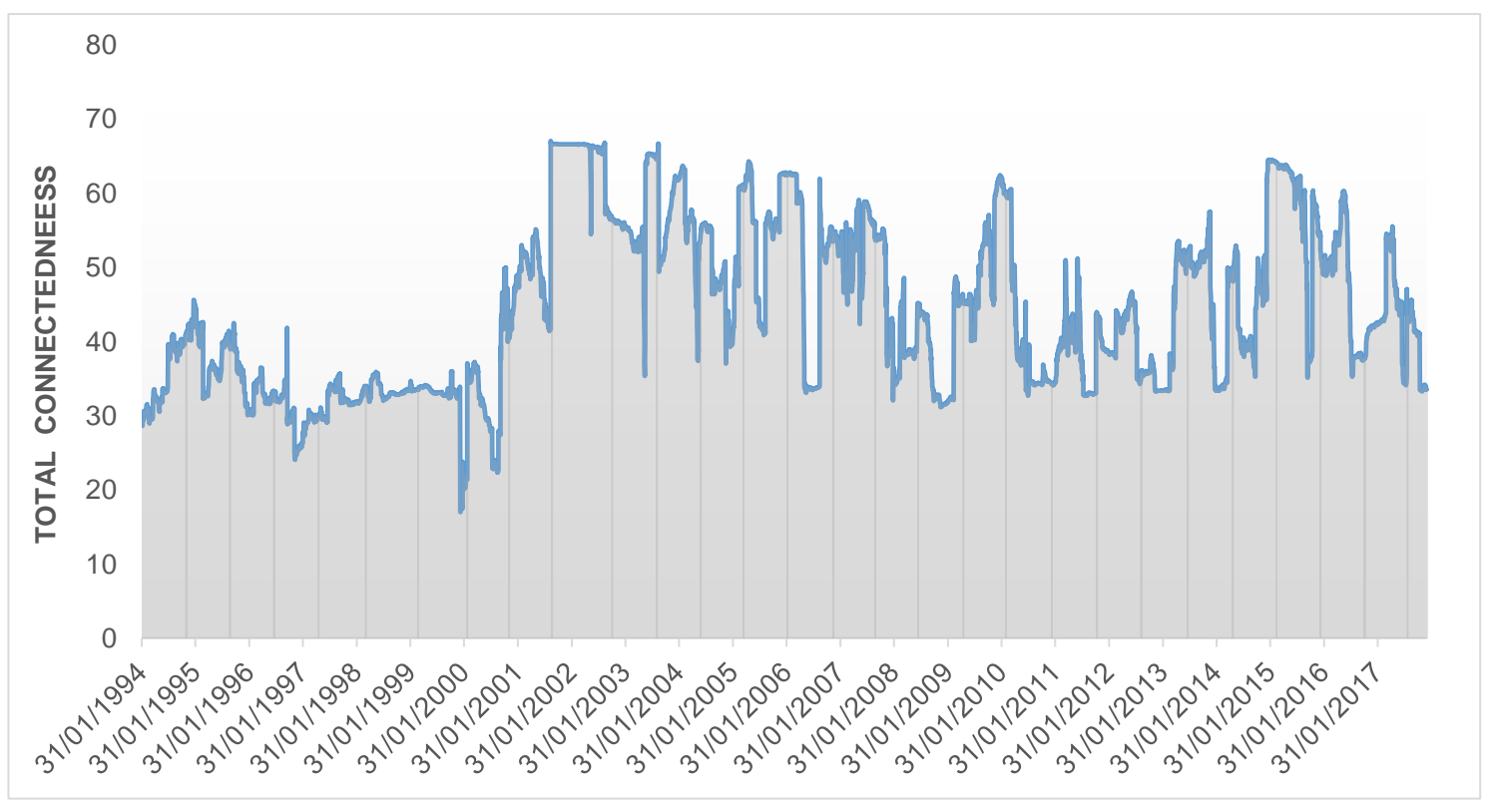

Figure 2. Total Terror index and Spanish stock market returns connectedness (200-day rolling-sample windows). 

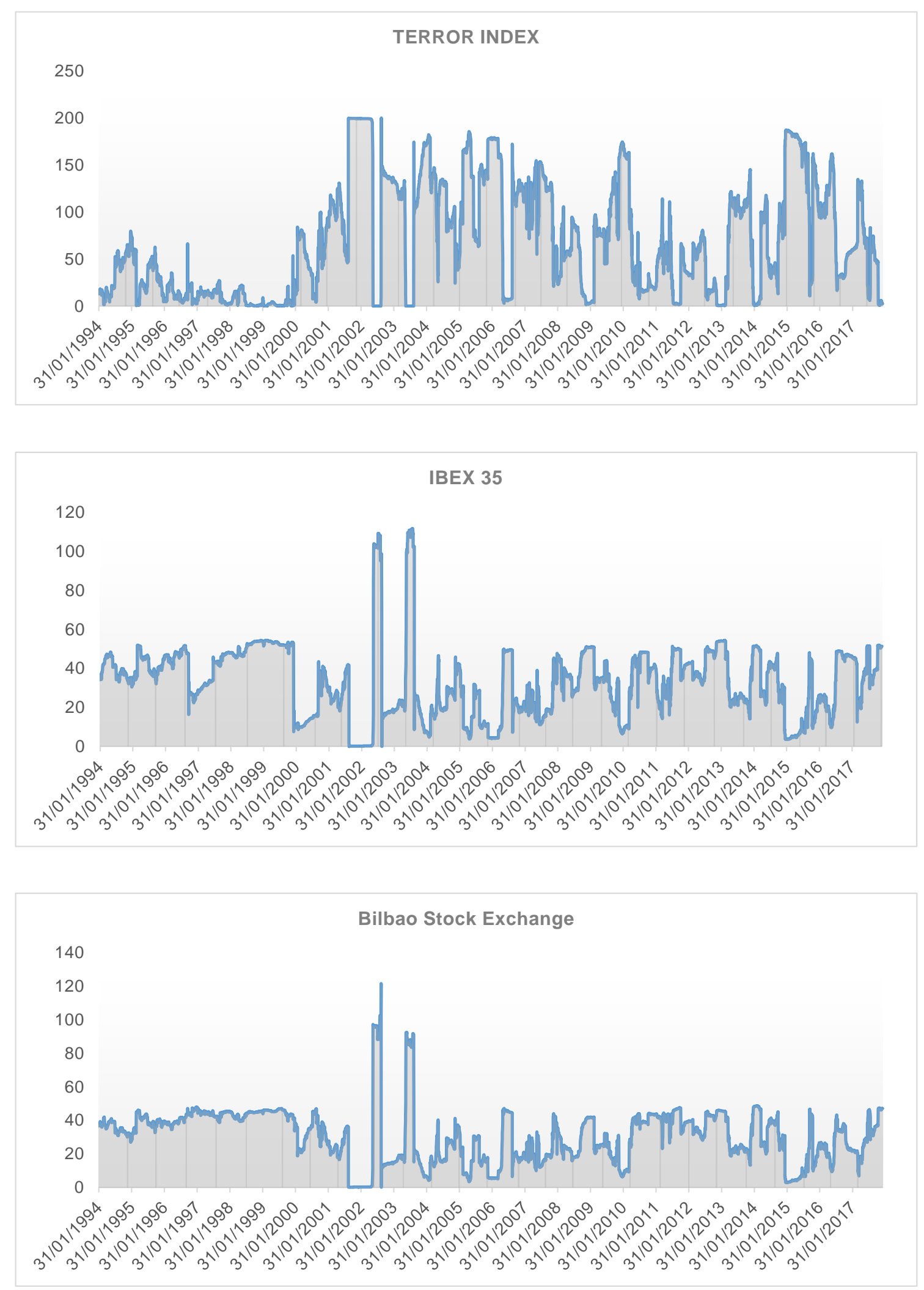

Figure 3. "To" connectedness Index (200-day rolling-sample windows). 

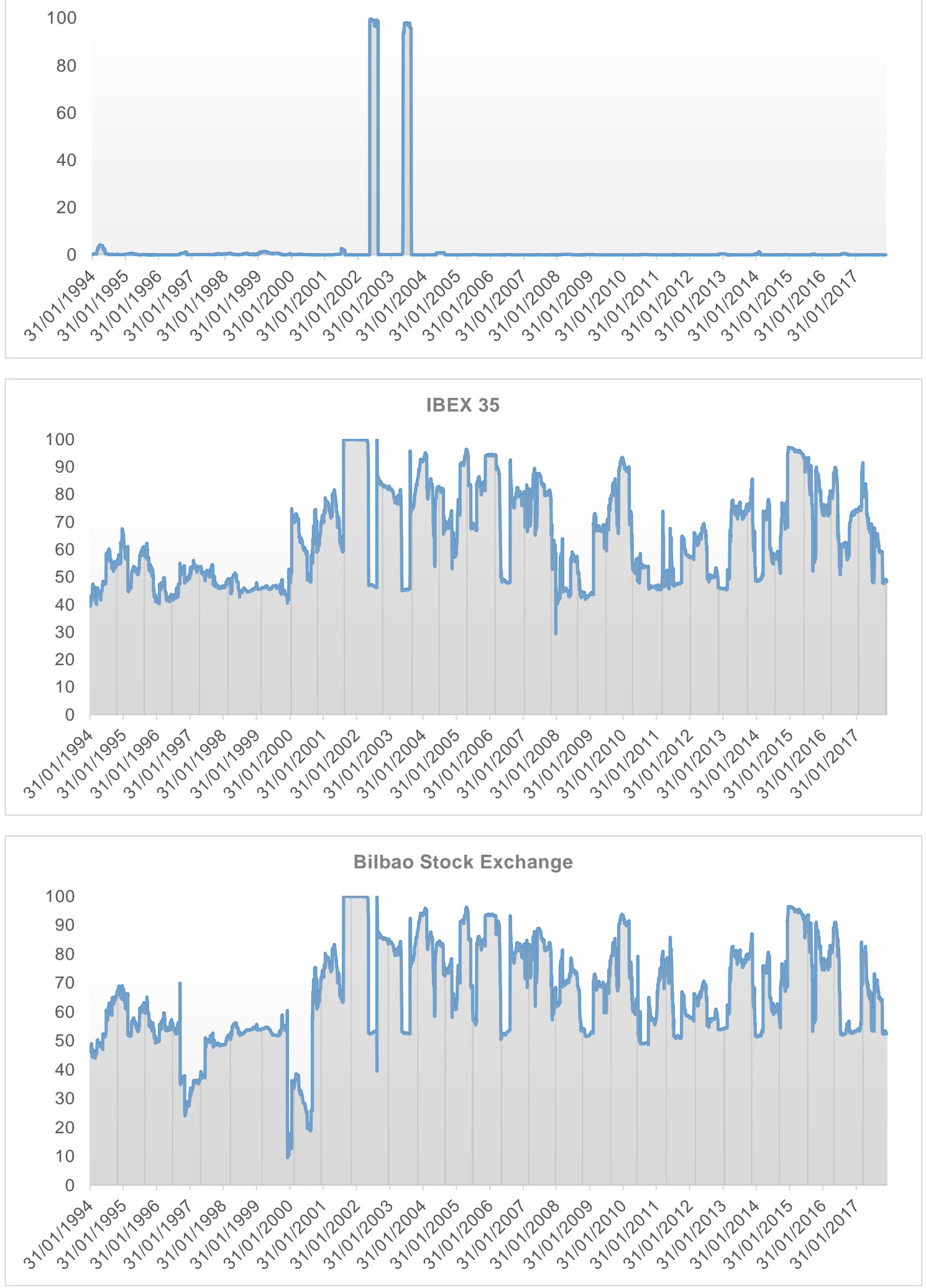

Figure 4. "From" connectedness Index (200-day rolling-sample windows). 


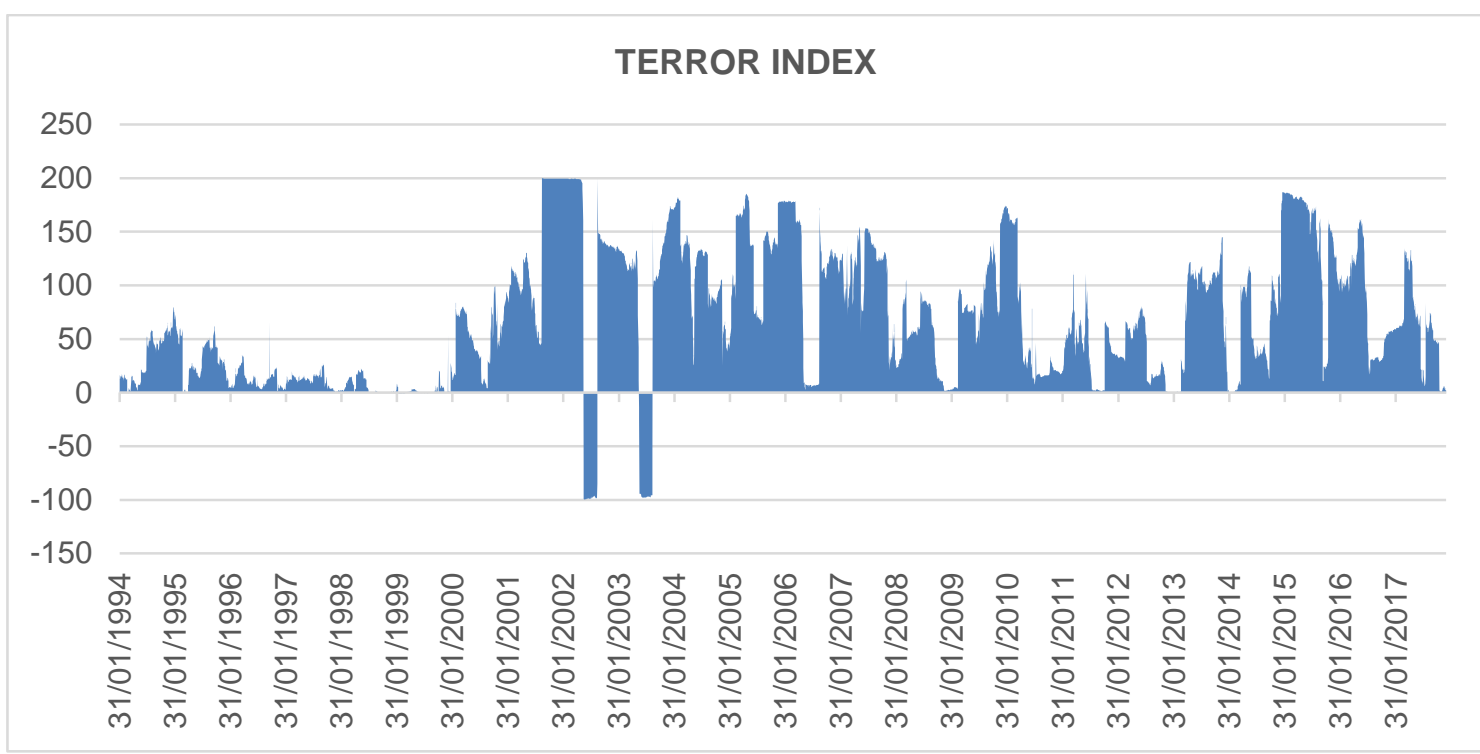

IBEX 35

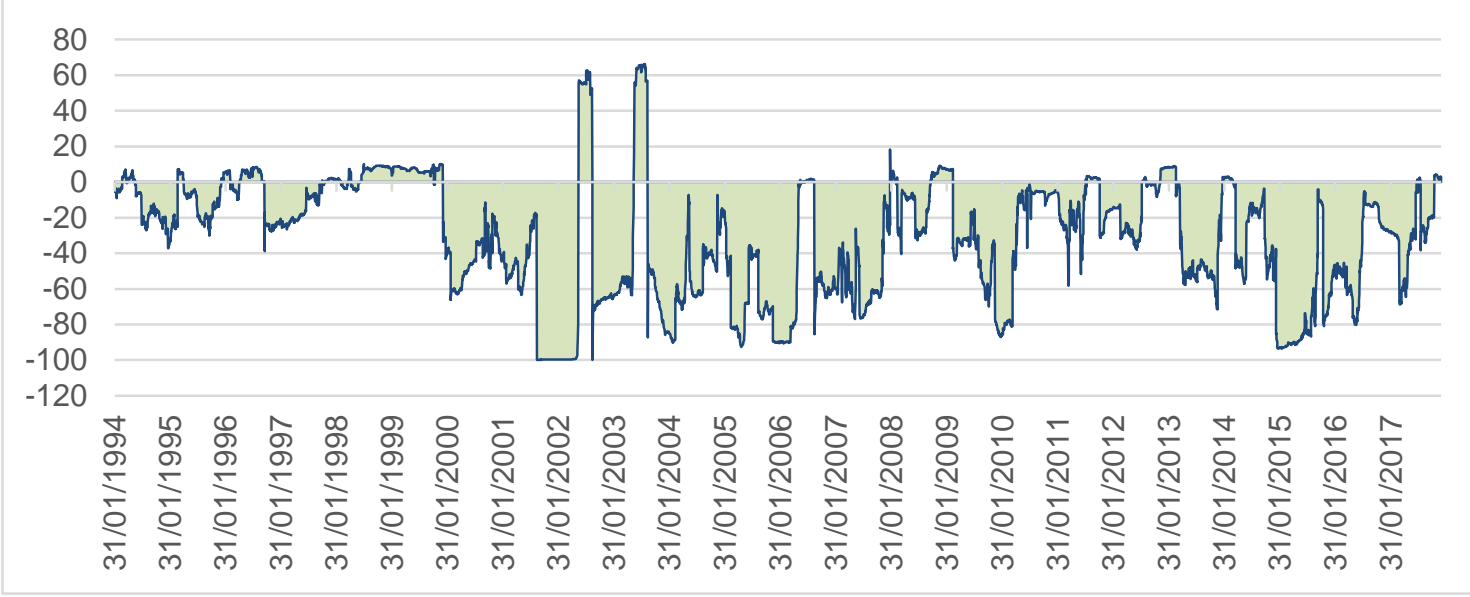

\section{Bilbao Stock Exchange}

100

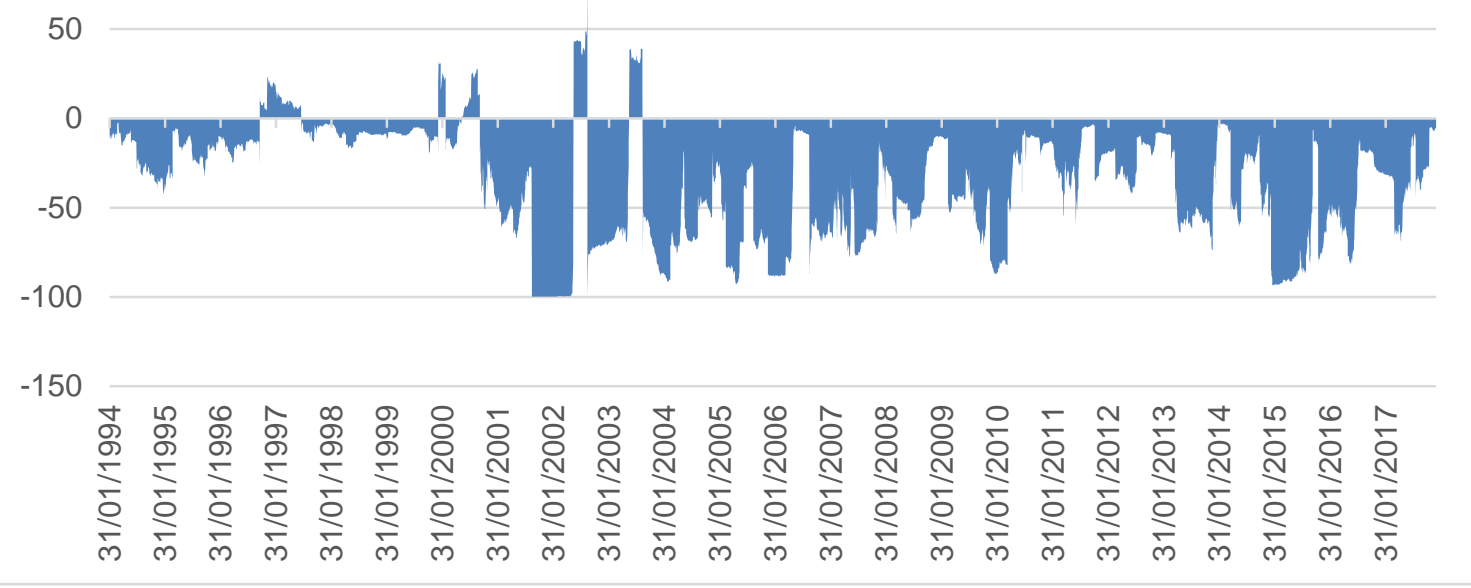

Figure 5. Net connectedness Index (200-day rolling-sample windows). 


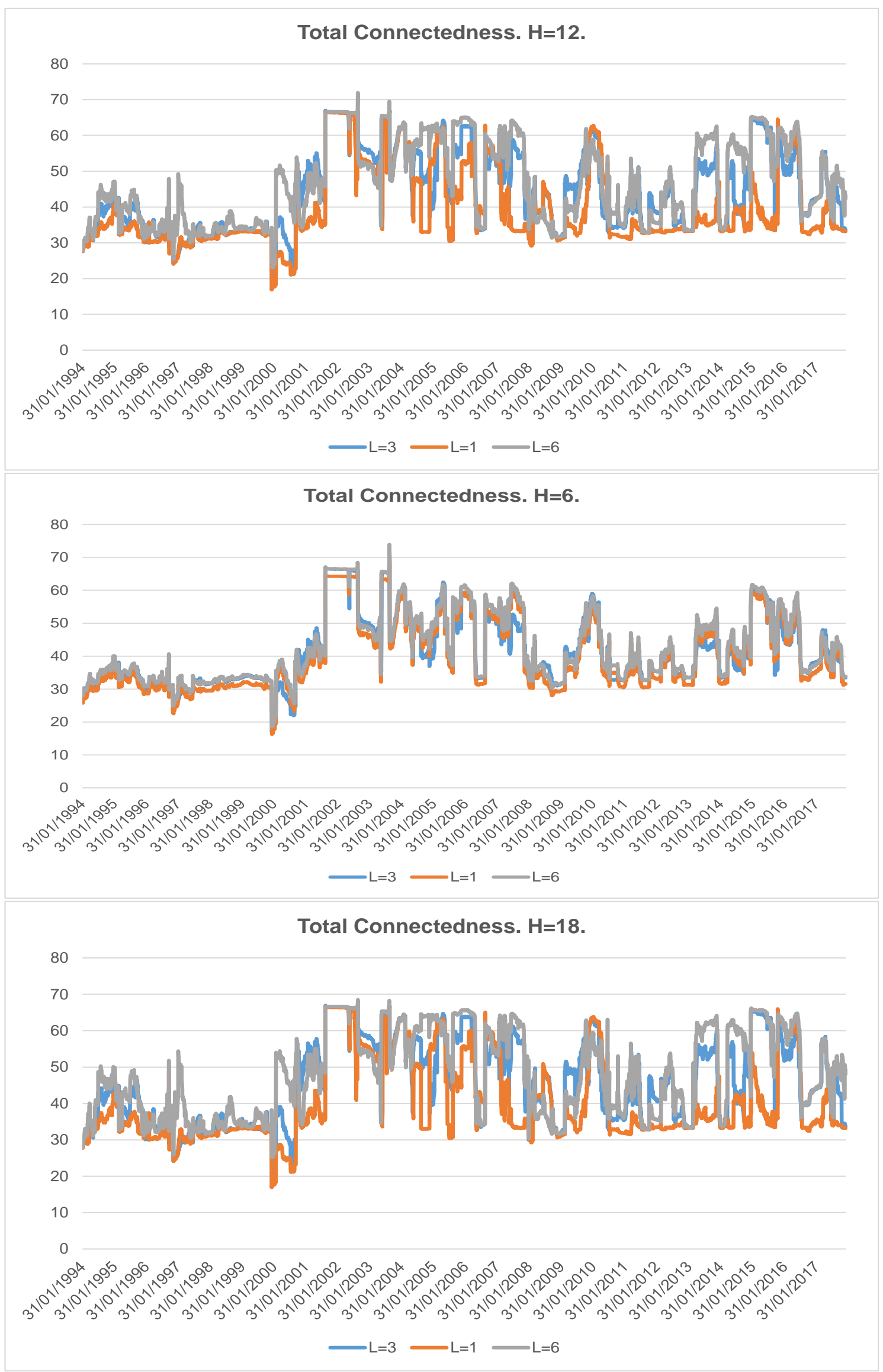

Figure 6. Robustness to forecast and lag choice: Total Terror index and Spanish stock market returns connectedness. 


\section{References}

Abadie, A., Gardeazabal, J., 2003. The economics costs of conflict: a case of study of the Basque country, American Economic Review, 93(1), 113-132.

Apergis, E., Apergis, N., 2016. The 11/13 Paris terrorist attacks and stock prices: the case of international defense industry, Finance Research Letters, 17, 186-192.

Arin, K., Ciferri, D., Spagnolo, N., 2008. The price of terror: the effects of terrorism on stock market returns and volatility, Economics Letters, 101, 164-167.

Barros, C., Alana, L., 2009. Stock market returns and terrorist violence: evidence from the Basque country, Applied Economic Letters, 16(15), 1575-1579.

Bloomberg S., Hess, G., Orphanides, A., 2004. The macroeconomic consequences of terrorism, Journal of Monetary Economics, 51, 1007-1032.

Chesney, M., Reshetar, G., Karaman, M., 2011. The impact of terrorism on financial markets: an empirical study, Journal of Banking and Finance, 35, 253-267.

Clemente, J, Montañes, A., Reyes, M., 1998. Testing for a unit root in variables with a double change in the mean, Economic Letters, 59, 175-182.

Diebold, F., Yilmaz, K., 2009. Measuring financial asset return and volatility spillovers, with application to global equity markets, The Economic Journal, 119, 158-171.

Diebold, F., Yilmaz, K., 2012. Better to give than to receive: predictive directional measurement of volatility spillovers, International Journal of Forecasting, 28, 57-66.

Diebold, F., Yilmaz, K., 2014. On the network topology of variance decompositions: measuring the connectedness of financial firms, Journal of Econometrics, 182, 119-134.

Diebold, F., Yilmaz, K., 2015. Financial and Macroeconomic Connectedness, place of publication: Oxford University Press. 
Dorta, A., Jiménez, J., Alemán, A., 2016. The impact of ETA’s dissolution on domestic tourism in Spain, Defence and Peace Economics, 27(6), 854-870.

Drakos, K. 2010. Terrorism activity, investor sentiment and stock returns, Review of Financial Economics, 19, 128-135.

Drakos, K. 2011. Behavioral channels in the cross-market diffusion of major terrorism shocks, Risk Analysis, 31(1), 143-159.

Drakos, K., Kallandranis, C., 2015. A note on the effect of terrorism on economic sentiment, Defence and Peace Economics, 26(6), 600-608.

Drakos, K., Kutan, A., 2003. Regional effects of terrorism on tourism in three Mediterranean countries, Journal of Conflict Resolution, 47(5), 621-641.

Eckstein, Z., Tsiddon, D., 2004. Macroeconomic consequences of terror: theory and the case of Israel, Journal of Monetary Economics, 51, 970-1002.

Enders, W., Sandler, T., 1991. Causality between transnational terrorism and tourism: the case of Spain, Terrorism, 14(1), 49-58.

Fielding, D., 2003. Modelling political instability and economic performance: israeli investment during the Intifada, Economica, 70 (277), 159-186.

Global Terrorism Index, 2017

Jetter, M., 2017. The effect of media attention on terrorism, Journal of Public Economics, 153, 32-48.

Katos, K., Liebert, H., Schulze, G., 2011. On the origin of domestic and international terrorism, European Journal of Political Economy, 27(S1), 17-36. 
Kolaric, S., Schiereck, D. 2016. Are stock markets efficient in the face of fear? Evidence from the terrorist attacks in Paris and Brussels, Finance Research Letters, 18, 306-310.

Kollias, C., Papadamou, S., Stagiannis, A., 2011. Terrorism and capital markets: the effects of the Madrid and London bomb attacks, International Review of Economics and Finance, 20, 532-541.

Koop, G., Pesaran, M., Potter, S., 1996. Impulse response analysis in non-linear multivariate models, Journal of Econometrics, 74, 119-147.

Leoniso, R., Molina, F., Muro, D. 2017. ETA’s terrorist campaign: From violence to politics, 1968-2015. Extremism and Democracy, Abingdon: Routledge.

Mehmood, S., 2014. Terrorism and the macroeconomy: Evidence from Pakistan, Defence and Peace Economics, 25(5), 509-534.

Pesaran, M, Shin, Y., 1998. Generalized impulse response analysis in linear multivariate models, Economic Letters, 58, 17-29.

Rodríguez, J., Rodríguez, J., Salas, R., Suarez-Pandiello, J., 2009. Quantifying fear: the social impact of terrorism, Journal of Policy Modelling, 31, 803-817.

Slovic, P., 2009. Concern of risk, Science, 236, 280-285. 